\title{
Tidal Flow-Volume Loop Enveloping at Rest in Advanced COPD
}

\author{
Luiz Felipe Fröhlich, Fernanda Machado Balzan, Franciele Plachi, Ricardo Gass, \\ Nathalia Branco Schweitzer Mendes, Danton Pereira da Silva Jr, Paulo Robero Stefani Sanches, \\ Marli M Knorst, J Alberto Neder, and Danilo Cortozi Berton
}

\begin{abstract}
BACKGROUND: Expiratory flow limitation (EFL) is a key physiological abnormality in COPD. Comparing tidal-to-maximum flow-volume (F-V) loops is a simple and widely available method to assess EFL in patients with COPD. We aimed to investigate whether subjects with COPD showing significant resting tidal F-V enveloping (ie, $>50 \%$ tidal volume) would present with higher exertional operating lung volumes, which would lead to greater burden of dyspnea and poorer exercise tolerance compared to their counterparts. METHODS: 37 subjects with COPD (21 males; $63.1 \pm 9.2$ years old; $\mathrm{FEV}_{1}=37 \pm 12 \%$ predicted) and 9 paired controls ( 3 males; $55.9 \pm 11.7 \mathrm{y}$ old) performed an incremental cardiopulmonary exercise testing on a cycle ergometer. Dyspnea perception, inspiratory capacity maneuvers after 3-4 sequential tidal F-V loops, and esophageal and gastric pressures were measured during exercise. RESULTS: Most subjects (31 of 37, 84\%) presented with significant tidal F-V enveloping. Critical inspiratory constraints and upward dyspnea inflection points (as a function of both work rate and ventilation) were reached earlier in these subjects, thereby leading to poorer exercise tolerance compared to their counterparts $(P=.01)$. Abdominal muscle recruitment (ie, increase in gastric pressure $\geq 15 \%$ ) during tidal expiration was significantly higher in the EFL + group. However, this did not bear an influence on the operating lung volumes, inspiratory constraints, dyspnea, cardiocirculatory responses, or exercise tolerance $(P>$.05). CONCLUSIONS: Tidal F-V loop enveloping at rest should be valued as it is related to relevant clinical outcomes, such as dyspnea burden and exercise tolerance in subjects with COPD. Key words: chronic obstructive pulmonary disease; exercise; dyspnea; pulmonary function tests; maximum expiratory flow-volume curves; airway resistance. [Respir Care 2019;64(12):1488-1499. (C) 2019 Daedalus Enterprises]
\end{abstract}

\section{Introduction}

Increased airway resistance and loss of lung elastic recoil due to highly variable combinations of chronic bron-

\footnotetext{
Mr Fröhlich, Ms Plachi, Mr Gass, and Drs Balzan, Mendes, Knorst, and Berton are affiliated with Programa de Pós-Graduação em Ciências Pneumológicas, Universidade Federal do Rio Grande do Sul, Rio Grande do Sul, Brazil. Mr Pereira da Silva Jr and Drs Sanches, Balzan, Mendes, Knorst, and Berton are affiliated with Hospital de Clínicas de Porto Alegre, Rio Grande do Sul, Brazil. Dr Neder is affiliated with the Laboratory of Clinical Exercise Physiology, Kingston Health Science Center \& Queen's University, Kingston, Ontario, Canada.

Dr Balzan presented a version of this paper at the Brazilian Pulmonology Society Congress, held August 2018, in Goiânia, Brazil.
}

The authors disclose relationships with Conselho Nacional de Desenvolvimento Científico e Tecnológico (grant 14/2013: 476356/2013), chitis and emphysema are associated with tidal expiratory flow limitation (EFL) in patients with COPD. ${ }^{1}$ The resultant gas trapping increases operating lung volume, thereby decreasing the volume available for tidal expansion. ${ }^{2}$ Consequently, increasing intrapleural pressures through active recruitment of the expiratory abdominal muscles characteristically fails to increase expiratory flow in these pa-

\footnotetext{
Coordenação de Aperfeiçoamento de Pessoal de Nível Superior, and the Incentive Fund of Research of HCPA (grant 14-0041).

Correspondence: Danilo C Berton MD PhD, Respiratory Division, Hospital de Clínicas de Porto Alegre, Federal University of Rio Grande do Sul, Rua Ramiro Barcelos 2350, Room 2250, Porto Alegre, Rio Grande do Sul, Brazil 90035-003. E-mail: dberton@ hcpa.edu.br.
}

DOI: $10.4187 /$ respcare. 06787 
tients. ${ }^{3}$ Therefore, this strategy is unable to appreciably decrease operating lung volume. ${ }^{1-5}$ As a consequence of progressive mechanical inspiratory constraints, there is a marked dissociation between neural motor input and lungchest wall displacement (ie, neuromechanical uncoupling), ${ }^{4}$ a phenomenon germane to dyspnea and exercise intolerance in patients with moderate to severe COPD. ${ }^{1,2,4}$ It is therefore important to estimate the presence and severity of tidal EFL because both dyspnea and exercise capacity are strong determinants of health-related quality of life in these patients. 6,7

Identification and quantification of tidal EFL is not a trivial task. ${ }^{8-11}$ Most currently available methods (eg, negative expiratory pressure $)^{12}$ remain largely constrained to the realm of research because it has been inaccessible to front-line practitioners. The simplest approach for cardiopulmonary exercise testing (CPET) available in most systems involves the visual comparison between the maximum and tidal flow-volume (F-V) loops recorded before an incremental CPET: EFL is assumed to be present if the expiratory tidal flow impinges on or overcomes the maximum expiratory flow at a given lung volume for a sizable fraction of tidal volume, and this is known as tidal F-V enveloping. ${ }^{8-11}$ Several studies have reported that subjects with COPD showing high operating lung volumes on exertion, which is an expected consequence of EFL when breathing frequency increases and expiratory time decreases, ${ }^{8}$ commonly present with tidal F-V enveloping. ${ }^{1,2,4,13}$ This method, however, has several potential limitations. For instance, tidal and maximum loops are characterized by different rates of sequential emptying of the lung with vastly uneven time constants; moreover, the preceding inspiration is associated with dissimilar time and volume history of the lung parenchyma and airways. ${ }^{8,9}$ It is also questionable whether the maximum $\mathrm{F}-\mathrm{V}$ provides a reasonable estimate of the flow limits at a given volume ${ }^{14}$ particularly in the presence of increased (small) airway compressibility/collapsibility. ${ }^{15}$ Thus, it remains unclear whether the inherent limitations of the tidal F-V loop enveloping approach are severe enough to interfere with its potential usefulness in predicting dyspnea burden and exercise intolerance in patients with COPD.

In this study, therefore, we primarily aimed to investigate whether subjects with COPD showing significant resting tidal F-V enveloping (ie, $>50 \%$ tidal volume) $)^{11,13}$ would present with higher operating lung volumes, leading to limiting dyspnea and poorer exercise tolerance compared to their counterparts. Secondarily, we reasoned that indirect evidence in favor of EFL would derive from the observation that active expiratory abdominal muscle recruitment (as inferred by increased intragastric pressure) ${ }^{3}$ fails to decrease the operating lung volumes in the former group. Together these findings would provide novel evidence that assessing the presence of resting tidal F-V en-

\section{QUICK LOOK}

\section{Current knowledge}

Expiratory flow limitation (EFL) occurs when flow cannot be further increased by increasing expiratory muscle effort. Comparison of tidal-to-maximum flow-volume loops is an old concept used to detect EFL that has potential limitations and has not been clinically validated against patient-centered outcomes.

\section{What this paper contributes to our knowledge}

Significant tidal-to-maximum flow-volume enveloping at rest (ie, $>50 \%$ of tidal volume) identified COPD subjects who presented with worse lung mechanics on exertion, higher dyspnea burden, and poorer tolerance of physical effort. This method can be used to predict which patients are more likely to reach critically high ventilatory constraints on exertion, an important prerequisite for effective treatment of breathlessness due to exertion.

veloping provides clinically relevant information related to exertional dyspnea and exercise intolerance in patients with COPD.

\section{Methods}

This cross-sectional study received ethical approval from the institutional ethical committee (14-0041) of the Hospital de Clínicas de Porto Alegre (Brazil). After obtaining informed consent, subjects completed 3 visits, which included clinical evaluation, resting pulmonary function tests, and an incremental, symptom-limited, cycling CPET. Before entering into the study, subjects were required to be clinically stable (ie, no hospitalization or clinical worsening) without any change in COPD medications in the 2 months before enrollment. They were instructed to keep using their medicines during all study visits and to avoid caffeinated beverages, alcohol, and heavy meals at least $4-6 \mathrm{~h}$ prior to the study procedures, as well as to avoid strenuous physical exertion for at least $12 \mathrm{~h}$ before the CPET visit. The COPD subjects received $400 \mu \mathrm{g}$ salbutamol via a metered-dose inhaler $30 \mathrm{~min}$ before the exercise testing.

\section{Subjects}

Subjects with COPD ${ }^{16}\left(\mathrm{FEV}_{1} / \mathrm{FVC}<0.7, \mathrm{FEV}_{1} \leq 60 \%\right.$ of predicted, and a smoking history $\geq 10$ pack-years) without evidence of asthma or any other lung disease were recruited from our respirology out-patient clinic between 

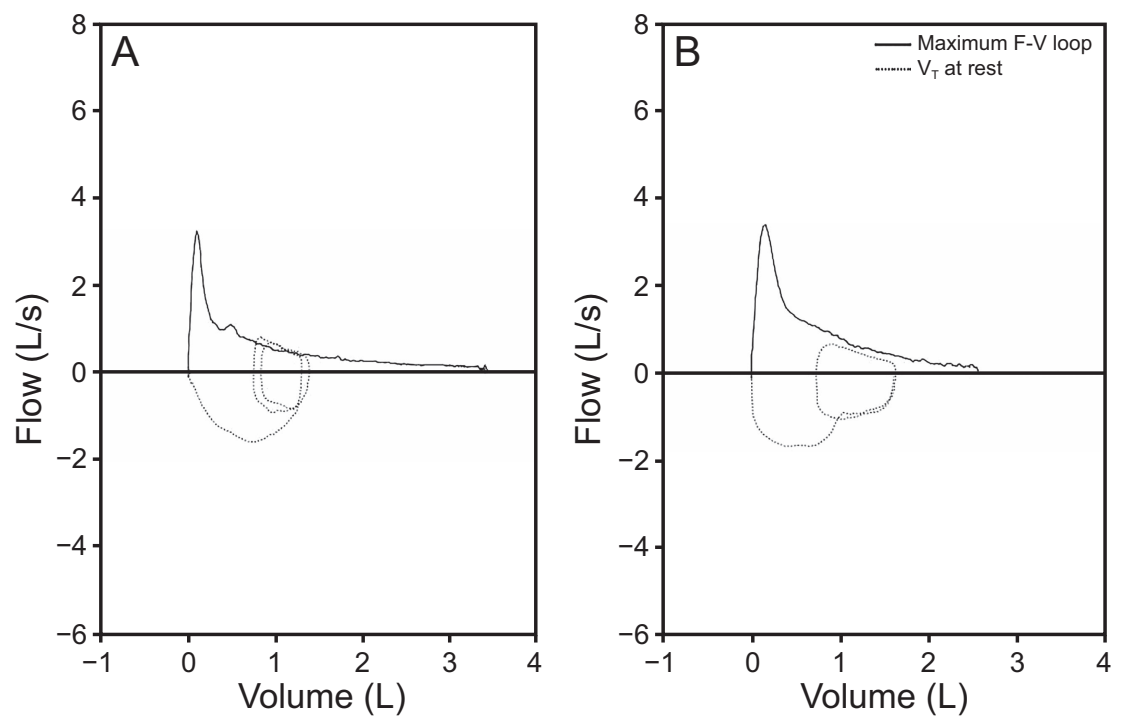

Fig. 1. Maximum and tidal flow-volume (F-V) loops in representative subjects with COPD at rest presenting with $(A)$ or without $(B)$ significant tidal F-V enveloping (ie, $>50 \%$ of the average tidal F-V loops meet or exceed the expiratory boundary of the maximum loop).

August 2015 and December 2017. Exclusion criteria also included the presence of any cardiovascular comorbidity or other medical conditions that could contribute to dyspnea or exercise limitation, contraindications to exercise testing, or severe hypoxemia at rest. Age- and sex-matched nonsmoking controls without COPD were included for comparison.

\section{Resting Lung Function Testing}

Spirometry, body plethysmography, and diffusing capacity of the lung for carbon monoxide were performed with a computerized system (CPF, Eric Jaeger GmbH, Würzburg, Germany). Maximum inspiratory $\left(\mathrm{P}_{\operatorname{Imax}}\right)$ and expiratory $\left(\mathrm{P}_{\mathrm{Emax}}\right)$ mouth-occlusion pressure were obtained with a pressure transducer (MVD300, Globalmed; Porto Alegre, Brazil). All tests were performed according to recommended standards. ${ }^{17-20}$ Results were expressed as absolute values and percent of predicted values according to national reference values. ${ }^{21-23}$

\section{CPET}

The exercise tests were performed on an electronically braked cycle ergometer (Corival, Lode, Gröningen, The Netherlands). Standard measurements of oxygen uptake $\left(\dot{\mathrm{V}}_{\mathrm{O}_{2}}\right)$, carbon dioxide production $\left(\dot{\mathrm{V}}_{\mathrm{CO}_{2}}\right)$, heart rate, minute ventilation $\left(\dot{\mathrm{V}}_{\mathrm{E}}\right)$, breathing frequency (f), and tidal volume $\left(\mathrm{V}_{\mathrm{T}}\right)$ were collected breath-by-breath with a CPET system (Vmax Encore System, CareFusion, Yorba Linda, CA). The exercise protocol consisted of a steady-state resting period of $5 \mathrm{~min}$, a subsequent 2-min warm-up of unloaded pedaling, followed by an incremental exercise phase of $5 \mathrm{~W}$ each minute until exhaustion (controls performed in increments of $10-20 \mathrm{~W} / \mathrm{min}$ ); pedaling frequency was maintained at approximately 60 revolutions/min. ${ }^{24,25}$ Subjects rated shortness of breath and leg effort every $2 \mathrm{~min}$ using the 10-point Borg scale. ${ }^{26} \mathrm{~S}_{\mathrm{pO}_{2}}$ was measured continuously (Oxicap, Takaoka, São Paulo, Brazil). After 3-4 sequential tidal F-V loops, inspiratory capacity maneuvers were performed at rest, every 2 min during exercise, and at peak exercise (Vmax Encore System) ${ }^{27}$ Resting tidal F-V loops were superimposed on the maximum F-V ${ }^{11,13}$ obtained from at least 3 acceptable and repeatable FVC maneuvers performed before exercise. To be used, a tidal breath had to be free of any noise or unwanted signals from swallowing, cough, or speech. ${ }^{10}$ EFL was considered significant if $>50 \%$ of the average tidal F-V loops met or exceeded (ie, enveloped) the expiratory boundary of the maximum loop (Fig. 1). ${ }^{11,13}$

Esophageal pressure and gastric pressure were obtained using thin-walled balloon catheters (Ackrad Laboratories, Cranford, New Jersey) coupled to differential pressure transducers. After local anesthesia of the nasal mucosa and pharynx, esophageal and gastric catheters were inserted through the nose and positioned in the lower third of the esophagus and in the stomach, respectively. ${ }^{28}$ Esophageal pressure and gastric pressure were continuously monitored with pressure sensors (MPX 7025 DP, Freescale Semiconductor, Texas) (Fig. 2). The pressure signals were obtained at $200 \mathrm{~Hz}$ using a 10-bit analog-to-digital converter. Custom software developed in a Visual Basic platform and used in previous studies from our lab was used to display data in real time on the computer monitor and storage for further analysis. ${ }^{28,29}$ Because the data from the balloon catheters and the pneumotachograph (Vmax Encore 
A

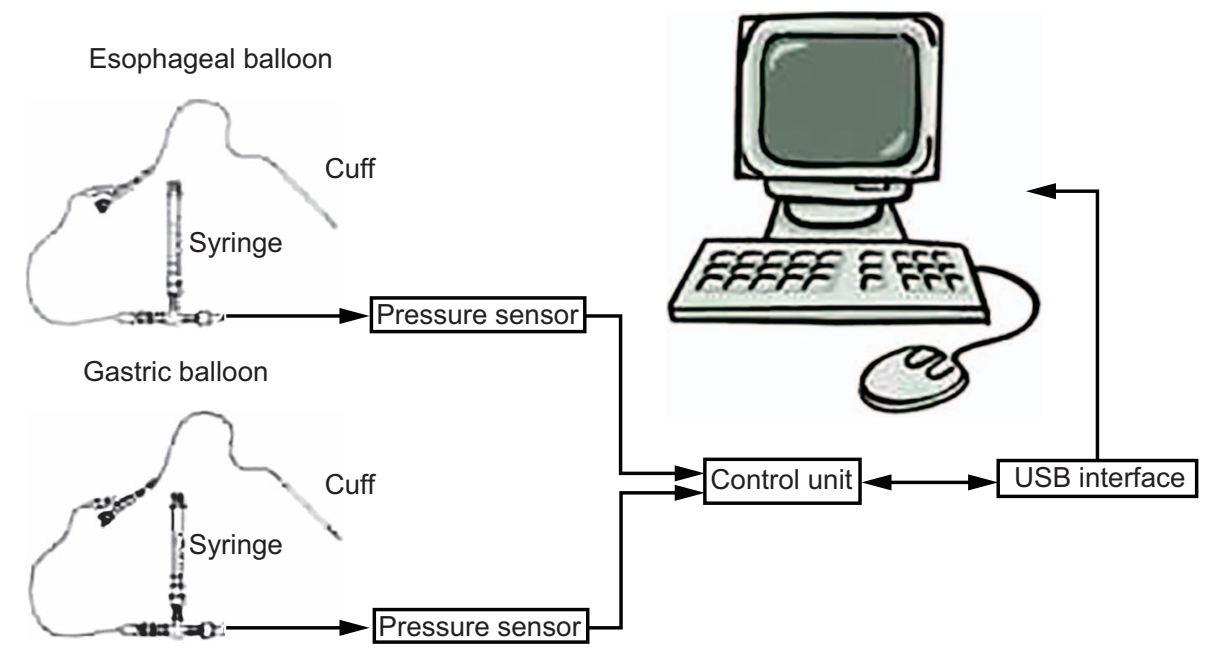

B

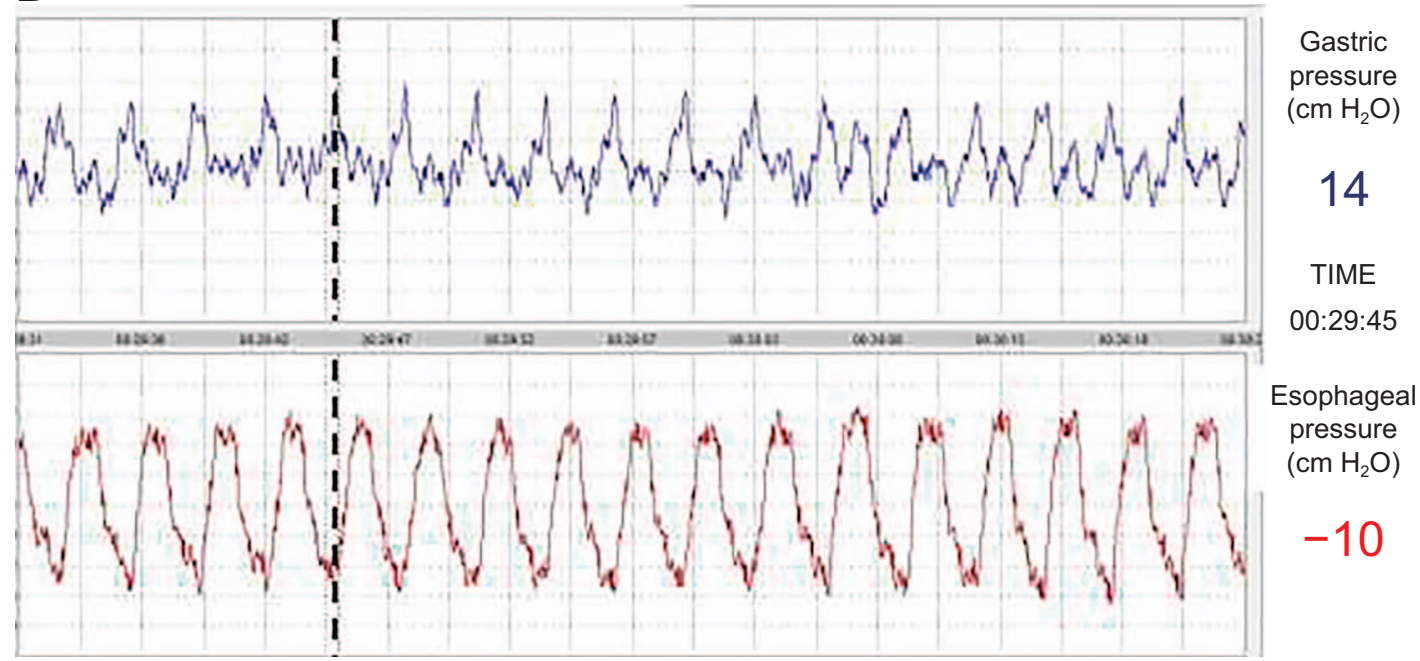

Fig. 2. A. Schematic of the system used to monitor esophageal and gastric pressure, with a reading range from $255 \mathrm{~cm} \mathrm{H}_{2} \mathrm{O}(187.5 \mathrm{~mm} \mathrm{Hg}=$ $25 \mathrm{kPa})$ to $-255 \mathrm{~cm} \mathrm{H}_{2} \mathrm{O}(-187.5 \mathrm{~mm} \mathrm{Hg}=-25 \mathrm{kPa})$. B. The pressures registered during a selected inspiratory tidal volume (dashed line).

System) were not computerized synchronously, manual markers in the pressure traces were inserted to identify specific breathing movements (eg, tidal volume, $\mathrm{P}_{\text {Imax }}$, FVC) and moments (eg, rest, $10 \mathrm{~W}$, etc.) for post hoc analysis in relation to its corresponding volume. Expiratory gastric pressure was the most positive value during tidal volume expiration. Expiratory gastric pressure was expressed relative to maximum gastric pressure obtained during the pre-exercise FVC maneuvers. An increase in the ratio of expiratory gastric pressure to FVC gastric pressure of $\geq 15 \%$ from rest to peak exercise was considered indicative of excessive abdominal muscle recruitment. ${ }^{3}$

\section{Statistical Analysis}

Continuous data are presented as mean \pm SD unless otherwise stated, whereas categorical data are presented as $n(\%)$. Differences among baseline characteristics were compared with analysis of variance tests. Exercise testing parameters were analyzed within and between groups at rest and at commonly standardized work rates (ie, rest, $10 \mathrm{~W}, 20 \mathrm{~W}, 30 \mathrm{~W}$, and peak) using a generalized estimated equation model with Bonferroni adjustments for multiple comparisons. SPSS 22.0.0.1 (SPSS, Chicago, IL) was used for the statistical analyses. The level of statistical significance was set at $P<.05$.

Considering that this was an observational, clinical physiology study, and estimating the prevalence of resting EFL in the COPD group at $\sim 70 \%, 30,31$ the sample size was estimated as 36 subjects with COPD; we sought to obtain a minimum sample of 12 subjects without resting EFL, which was enough to detect significant differences in a previous similar study analyzing the same clinical and physiological outcomes. ${ }^{32}$ Because of the complexity and 
Table 1. Baseline Subject Characteristics

\begin{tabular}{|c|c|c|c|}
\hline \multirow{2}{*}{ Variables } & \multirow{2}{*}{ Control $(n=9)$} & \multicolumn{2}{|c|}{ COPD $(n=37)$} \\
\hline & & $\mathrm{EFL}+(n=31)$ & $\mathrm{EFL}-(n=6)$ \\
\hline Male sex, $n(\%)$ & $3(33)$ & $15(48)$ & $6(100) * \dagger$ \\
\hline Age, y & $55.9 \pm 11.7$ & $61.8 \pm 9.9$ & $63.7 \pm 4.6$ \\
\hline Weight, kg & $66.6 \pm 14.4$ & $66.6 \pm 14.2$ & $71.2 \pm 13.9$ \\
\hline Height, cm & $163.7 \pm 9.7$ & $162.3 \pm 7.9$ & $169.8 \pm 3.6$ \\
\hline Body mass index, $\mathrm{kg} / \mathrm{m}^{2}$ & $24.7 \pm 3.1$ & $25.3 \pm 5.1$ & $24.7 \pm 5.1$ \\
\hline \multicolumn{4}{|l|}{ Resting lung function } \\
\hline $\mathrm{FEV}_{1}, \mathrm{~L}$ & $2.81 \pm 0.56$ & $1.01 \pm 0.34^{*}$ & $1.41 \pm 0.36^{* \dagger}$ \\
\hline $\mathrm{FEV}_{1}, \%$ predicted & $98 \pm 7$ & $36 \pm 12 *$ & $42 \pm 11^{*}$ \\
\hline $\mathrm{FEV}_{1}$ post $\mathrm{BD}, \mathrm{L}$ & NA & $1.08 \pm 0.42$ & $1.49 \pm 0.46 \dagger$ \\
\hline $\mathrm{FEV}_{1}$ post $\mathrm{BD}, \%$ predicted & NA & $38 \pm 14$ & $44 \pm 14$ \\
\hline FVC, L & $3.48 \pm 0.70$ & $1.94 \pm 0.54 *$ & $2.54 \pm 0.69 * \dagger$ \\
\hline FVC, $\%$ predicted & $97 \pm 8$ & $55 \pm 13 *$ & $59 \pm 15^{*}$ \\
\hline FVC post BD, L & NA & $2.12 \pm 0.58$ & $2.68 \pm 0.67 \dagger$ \\
\hline FVC post BD, \% predicted & NA & $60 \pm 14$ & $62 \pm 14$ \\
\hline $\mathrm{FEV}_{1} / \mathrm{FVC}, \%$ & $80 \pm 02$ & $52 \pm 10^{*}$ & $56 \pm 08 *$ \\
\hline $\mathrm{FEV}_{1} / \mathrm{FVC}$ post $\mathrm{BD}, \%$ & NA & $50 \pm 12$ & $55 \pm 08$ \\
\hline TLC, $\mathrm{L}$ & $5.72 \pm 0.88$ & $7.25 \pm 1.51^{*}$ & $7.20 \pm 0.93 *$ \\
\hline TLC, \% predicted & $109 \pm 9$ & $137 \pm 20^{*}$ & $112 \pm 13 \dagger$ \\
\hline Residual volume, L & $2.21 \pm 0.46$ & $5.12 \pm 1.33^{*}$ & $4.31 \pm 1.01 *$ \\
\hline Residual volume, $\%$ predicted & $133 \pm 25$ & $293 \pm 78^{*}$ & $199 \pm 50 * \dagger$ \\
\hline FRC, $\mathrm{L}$ & $3.04 \pm 0.59$ & $5.65 \pm 1,55$ & $5.40 \pm 1.20$ \\
\hline FRC, $\%$ predicted & $101 \pm 15$ & $181 \pm 47^{*}$ & $155 \pm 33^{*}$ \\
\hline $\mathrm{D}_{\mathrm{LCO}}, \%$ predicted & $79 \pm 11$ & $17 \pm 7^{*}$ & $21 \pm 9 *$ \\
\hline $\mathrm{P}_{\text {Imax }}, \mathrm{cm} \mathrm{H}_{2} \mathrm{O}$ & $-102.7 \pm 18.2$ & $-71.7 \pm 19.3 *$ & $-89.3 \pm 25.8$ \\
\hline $\mathrm{P}_{\text {Imax }}, \%$ predicted & $108 \pm 20$ & $70 \pm 20^{*}$ & $85 \pm 28$ \\
\hline $\mathrm{P}_{\mathrm{Emax}}, \mathrm{cm} \mathrm{H}_{2} \mathrm{O}$ & $130.2 \pm 44.3$ & $97.3 \pm 31.1$ & $140.0 \pm 18.1 \dagger$ \\
\hline $\mathrm{P}_{\text {Emax }}, \%$ predicted & $134 \pm 34$ & $85 \pm 29^{*}$ & $121 \pm 14 \dagger$ \\
\hline $\begin{array}{l}\text { Values are presented as } n(\%) \text { or mean } \pm \mathrm{SD} \\
* P<.05 \text { versus control group. } \\
\dagger P<.05 \mathrm{EFL}+\text { versus } \mathrm{EFL}- \\
\mathrm{EFL}=\text { expiratory flow limitation } \\
\mathrm{BD}=\text { bronchodilator } \\
\mathrm{NA}=\text { not applicable } \\
\mathrm{TLC}=\text { total lung capacity } \\
\mathrm{FRC}=\text { functional residual capacity } \\
\mathrm{D}_{\mathrm{LCO}}=\text { diffusing capacity of the lung for ca } \\
\mathrm{P}_{\text {Imax }}=\text { maximum inspiratory pressure } \\
\mathrm{P}_{\text {Emax }}=\text { maximum expiratory pressure }\end{array}$ & & & \\
\hline
\end{tabular}

invasiveness of some of the measurements, a planned analysis was undertaken when this total sample had been included, and the study was interrupted when significant differences were found.

\section{Results}

Thirty-seven subjects with COPD were included: 21 males $(57 \%), 63.1 \pm 9.2$ years old, $\mathrm{FEV}_{1}=37 \pm 12 \%$ of predicted, and inspiratory capacity/total lung capacity ratio $=0.22 \pm 0.08$. As expected, all lung function parameters were significantly worse in subjects with COPD compared to controls (Table 1). Responses to exercise were typical of subjects with COPD, including reduced peak aer- obic capacity and ventilatory reserve $(975 \pm 225 \mathrm{~mL} / \mathrm{min}$ and $0.79 \pm 0.16$, respectively)..$^{24,25}$

Thirty-one subjects $(84 \%)$ presented with significant tidal F-V loop enveloping at rest $(\mathrm{EFL}+)$ in contrast to the remaining 6 subjects with COPD who did not show EFL (EFL-) and 9 healthy controls. Resting lung functional parameters adjusted for age, gender, and height (ie, expressed as percent of predicted value) were not different between subjects with COPD who presented with or without EFL, except for lower residual volume and total lung capacity in EFL - subjects. The majority of subjects demonstrated advanced disease (ie, postbronchodilator $\mathrm{FEV}_{1}<50 \%$ predicted), and the 
Tidal Flow-Volume Loop Enveloping in Advanced COPD

Table 2. Metabolic, Circulatory, Ventilatory, and Sensorial Responses From Rest to Peak Exercise

\begin{tabular}{|c|c|c|c|c|c|c|c|c|c|}
\hline \multirow[b]{3}{*}{ Variable } & \multirow{2}{*}{\multicolumn{3}{|c|}{ Control $(n=9)$}} & \multicolumn{6}{|c|}{ COPD } \\
\hline & & & & \multicolumn{3}{|c|}{$\mathrm{EFL}+(n=31)$} & \multicolumn{3}{|c|}{$\mathrm{EFL}-(n=6)$} \\
\hline & Rest & Isowork & Peak & Rest & Isowork & Peak & Rest & Isowork & Peak \\
\hline Work rate, $\mathrm{W}$ & NA & 20 & $118 \pm 12$ & NA & 20 & $41 \pm 3^{*}$ & NA & 20 & $59 \pm 7 * \dagger$ \\
\hline$\dot{\mathrm{V}}_{\mathrm{O}_{2}}, \mathrm{~L} / \mathrm{min}$ & $0.27 \pm 0.01$ & $0.58 \pm 0.03$ & $1.75 \pm 0.12$ & $0.45 \pm 0.03^{*}$ & $0.71 \pm 0.03 *$ & $0.95 \pm 0.04 *$ & $0.49 \pm 0.05^{*}$ & $0.74 \pm 0.06$ & $1.04 \pm 0.05 *$ \\
\hline$\dot{\mathrm{V}}_{\mathrm{O}_{2}}, \%$ predicted & $19 \pm 2$ & $42 \pm 4$ & $119 \pm 5$ & $32 \pm 2 *$ & $51 \pm 2$ & $68 \pm 3^{*}$ & $29 \pm 2 *$ & $43 \pm 3$ & $62 \pm 5^{*}$ \\
\hline$\dot{\mathrm{V}}_{\mathrm{O}_{2}}, \mathrm{~mL} / \mathrm{kg} / \mathrm{min}$ & $4.2 \pm 0.3$ & $8.9 \pm 0.4$ & $26.7 \pm 1.8$ & $6.7 \pm 0.4^{*}$ & $10.7 \pm 0.4 *$ & $14.4 \pm 0.6^{*}$ & $7.0 \pm 0.7^{*}$ & $10.6 \pm 0.8$ & $15.2 \pm 1.7^{*}$ \\
\hline$\dot{\mathrm{V}}_{\mathrm{CO}_{2}}, \mathrm{~L} / \mathrm{min}$ & $0.22 \pm 0.01$ & $0.46 \pm 0.02$ & $1.97 \pm 0.13$ & $0.37 \pm 0.02 *$ & $0.63 \pm 0.03 *$ & $0.94 \pm 0.05^{*}$ & $0.41 \pm 0.04 *$ & $0.66 \pm 0.04 *$ & $1.09 \pm 0.08^{*}$ \\
\hline Heart rate, beats/min & $74 \pm 3$ & $88 \pm 4$ & $151 \pm 7$ & $82 \pm 3$ & $99 \pm 3$ & $120 \pm 3^{*}$ & $92 \pm 4 *$ & $102 \pm 4 *$ & $129 \pm 4^{*}$ \\
\hline Heart rate, $\%$ predicted & $45 \pm 2$ & $53 \pm 2$ & $92 \pm 3$ & $52 \pm 2^{*}$ & $62 \pm 2^{*}$ & $76 \pm 2 *$ & $59 \pm 2 * \dagger$ & $65 \pm 2^{*}$ & $83 \pm 3$ \\
\hline $\mathrm{O}_{2}$ pulse, mL/beat & $3.7 \pm 0.2$ & $6.7 \pm 0.4$ & $11.7 \pm 0.8$ & $5.8 \pm 0.5^{*}$ & $7.3 \pm 0.4$ & $8.0 \pm 0.4 *$ & $5.3 \pm 0.4^{*}$ & $7.3 \pm 0.5$ & $8.0 \pm 0.4^{*}$ \\
\hline$\dot{\mathrm{V}}_{\mathrm{E}}, \mathrm{L} / \mathrm{min}$ & $8.8 \pm 0.4$ & $14.2 \pm 0.7$ & $59.7 \pm 3.9$ & $14.9 \pm 0.8^{*}$ & $22.1 \pm 0.7^{*}$ & $32.3 \pm 1.4^{*}$ & $16.2 \pm 1.2^{*}$ & $22.5 \pm 2.4 *$ & $35.7 \pm 1.7^{*}$ \\
\hline $\mathrm{f}$, breaths/min & $15 \pm 1$ & $19 \pm 1$ & $33 \pm 1$ & $21 \pm 1 *$ & $22 \pm 1$ & $32 \pm 1$ & $20 \pm 1 *$ & $21 \pm 1$ & $26 \pm 1 * \dagger$ \\
\hline Tidal volume, $\mathrm{L}$ & $0.59 \pm 0.03$ & $0.78 \pm 0.05$ & $1.81 \pm 0.16$ & $0.75 \pm 0.04 *$ & $1.00 \pm 0.04 *$ & $1.03 \pm 0.05^{*}$ & $0.82 \pm 0.04 *$ & $1.06 \pm 0.09 *$ & $1.37 \pm 0.10 \dagger$ \\
\hline $\begin{array}{l}\text { Tidal volume/inspiratory } \\
\text { capacity, } \%\end{array}$ & $24 \pm 1$ & $29 \pm 1$ & $66 \pm 2$ & $40 \pm 2 *$ & $59 \pm 2 *$ & $68 \pm 1$ & $41 \pm 2 *$ & $52 \pm 5^{*}$ & $71 \pm 3$ \\
\hline Inspiratory capacity, L & $2.51 \pm 0.15$ & $2.66 \pm 0.16$ & $2.73 \pm 0.18$ & $1.92 \pm 0.09 *$ & $1.72 \pm 0.08 *$ & $1.52 \pm 0.06^{*}$ & $2.00 \pm 0.08^{*}$ & $2.06 \pm 0.12 *$ & $1.91 \pm 0.11^{*} \dagger$ \\
\hline $\begin{array}{l}\text { Change in inspiratory capacity } \\
\text { from rest, L }\end{array}$ & NA & $0.15 \pm 0.04$ & $0.22 \pm 0.05$ & NA & $-0.20 \pm 0.04 *$ & $-0.40 \pm 0.05^{*}$ & NA & $0.07 \pm 0.06 \dagger$ & $-0.08 \pm 0.10 * \dagger$ \\
\hline Inspiratory reserve volume, L & $1.91 \pm 0.14$ & $1.88 \pm 0.13$ & $0.92 \pm 0.06$ & $1.17 \pm 0.08^{*}$ & $0.71 \pm 0.06^{*}$ & $0.49 \pm 0.03 *$ & $1.18 \pm 0.09^{*}$ & $1.01 \pm 0.16^{*}$ & $0.54 \pm 0.07 *$ \\
\hline End-expiratory lung volume, L & $3.22 \pm 0.17$ & $3.07 \pm 0.19$ & $2.99 \pm 0.15$ & $5.27 \pm 0.25^{*}$ & $5.46 \pm 0.26^{*}$ & $5.66 \pm 0.27 *$ & $5.20 \pm 0.30^{*}$ & $5.13 \pm 0.28 *$ & $5.29 \pm 0.34 *$ \\
\hline $\begin{array}{l}\text { End-inspiratory lung } \\
\text { volume, } \mathrm{L}\end{array}$ & $3.81 \pm 0.17$ & $3.85 \pm 0.20$ & $4.80 \pm 0.30$ & $6.03 \pm 0.26^{*}$ & $6.47 \pm 0.26^{*}$ & $6.70 \pm 0.27 *$ & $6.02 \pm 0.31^{*}$ & $6.20 \pm 0.27^{*}$ & $6.66 \pm 0.36^{*}$ \\
\hline $\begin{array}{l}\text { End-inspiratory lung volume/ } \\
\text { TLC, } \%\end{array}$ & $67 \pm 1$ & $67 \pm 2$ & $84 \pm 1$ & $83 \pm 1 *$ & $90 \pm 1^{*}$ & $93 \pm 0^{*}$ & $83 \pm 1 *$ & $86 \pm 1^{*}$ & $92 \pm 1^{*}$ \\
\hline$\dot{\mathrm{V}}_{\mathrm{E}} / \dot{\mathrm{V}}_{\mathrm{CO}_{2}}$ & $40.4 \pm 2.0$ & $30.6 \pm 0.8$ & $30.3 \pm 0.7$ & $43.2 \pm 2.2$ & $37.5 \pm 1.8^{*}$ & $35.1 \pm 1.1 *$ & $40.4 \pm 3.1$ & $34.5 \pm 4.0$ & $34.1 \pm 3.3$ \\
\hline$\dot{\mathrm{V}}_{\mathrm{E}} / \dot{\mathrm{V}}_{\mathrm{CO}_{2}}$, slope & NA & NA & $26.6 \pm 2.4$ & NA & NA & $30.3 \pm 5.5^{*}$ & NA & NA & $30.3 \pm 10.1^{*}$ \\
\hline $\mathrm{S}_{\mathrm{pO}_{2}, \%}$ & $98.0 \pm 0.4$ & $98.0 \pm 0.5$ & $97.6 \pm 0.6$ & $97.3 \pm 0.3$ & $95.1 \pm 0.5^{*}$ & $93.1 \pm 0.7^{*}$ & $96.5 \pm 1.0$ & $95.5 \pm 1.3$ & $93.8 \pm 2.2$ \\
\hline Dyspnea, Borg units & 0 & $0.06 \pm 0.05$ & $3.44 \pm 0.86$ & $0.39 \pm 0.13^{*}$ & $2.16 \pm 0.37 *$ & $6.89 \pm 0.49 *$ & $0.25 \pm 0.16$ & $0.25 \pm 0.10 \dagger$ & $4.25 \pm 1.32$ \\
\hline Leg discomfort, Borg units & 0 & $0.22 \pm 0.11$ & $7.00 \pm 0.94$ & $0.31 \pm 0.12 *$ & $4.15 \pm 0.47^{*}$ & $8.19 \pm 0.36$ & $0.50 \pm 0.46$ & $2.08 \pm 0.82$ & $6.50 \pm 1.24$ \\
\hline $\begin{array}{l}\text { Values are presented as mean } \pm \mathrm{SE} . \\
* P<.05 \text { versus control group at a } \\
\dagger P<.05 \text { comparing COPD groups } \\
\dagger \mathrm{i} \\
\mathrm{EFL}=\text { expiratory flow limitation } \\
\mathrm{NA}=\text { not applicable } \\
\dot{\mathrm{V}}_{\mathrm{O}_{2}}=\text { oxygen consumption } \\
\mathrm{V}_{\mathrm{CO}_{2}}=\text { carbon dioxide production } \\
\mathrm{V}_{\mathrm{E}}=\text { expiratory minute ventilation } \\
\mathrm{f}=\text { breathing frequency } \\
\mathrm{TLC}=\text { total lung capacity }\end{array}$ & $\begin{array}{l}\text { ven moment (re } \\
\text { a given mome }\end{array}$ & $\begin{array}{l}\text { est, isowork, or } \mathrm{p} \\
\text { nt. }\end{array}$ & eak). & & & & & & \\
\hline
\end{tabular}

proportion of those presenting with moderate air-flow limitation $\left(50 \% \leq \mathrm{FEV}_{1}<79 \% \text { of predicted }\right)^{16}$ did not differ between EFL + and EFL - subjects (19\% and $17 \%$, respectively, $P>.05$ ).

Physiological and sensorial responses to exercise are summarized in Table 2 and presented in Figures 3 and 4. Despite similar ventilation (Fig. 3A), the EFL+ group showed a more pronounced decrement in inspiratory capacity (Fig. 3B) and reached critical operating lung volumes sooner (Fig. 3C). This was characteristically associated with a plateau in tidal volume expansion (Fig. 3D) and a sudden rise in $\mathrm{f}$ (Fig. 3E) and dyspnea perception toward intolerable levels (Fig. 3F). The EFL + group also reported higher dyspnea perception at isoventilation (Fig. 4A). Accordingly, tidal inspiratory muscle effort was significantly higher (Fig. 4B), particularly when adjusted for tidal volume expansion (Fig. 4C). Conversely, the EFLgroup behaved similarly to the control group.
We found that abdominal muscle recruitment during tidal expiration was significantly higher in the EFL + group compared to the EFL- and control groups (Fig. 4D). In fact, 16 of $31(\sim 50 \%)$ EFL + subjects developed excessive abdominal muscle recruitment, and this behavior was observed only in this group. Baseline resting ventilatory mechanics were not different among subjects with COPD according to the presence of excessive abdominal muscle recruitment during exercise (Table 3). Metabolic, circulatory, ventilatory, and sensory responses during exercise also were not different between these groups (Fig. 5).

\section{Discussion}

To our knowledge, this is the first study to show that EFL suggested by tidal F-V enveloping at rest is related to dyspnea and exercise intolerance, which are key negative clinical outcomes in subjects with COPD. We observed 

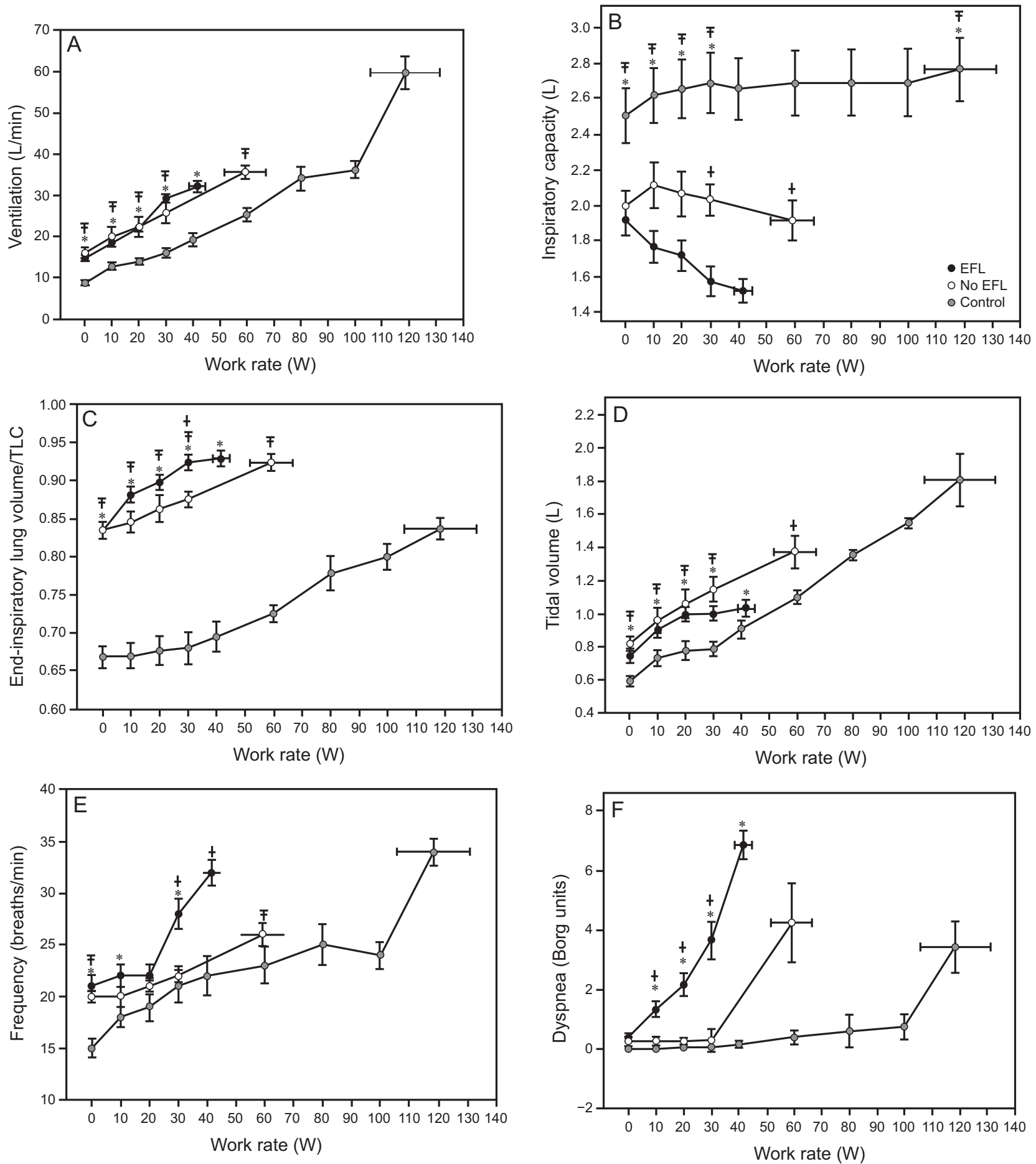

Fig. 3. Ventilatory mechanics, breathing pattern, and dyspnea perception in subjects with COPD with and without resting tidal expiratory flow limitation (EFL) suggested by significant tidal flow-volume enveloping and in control subjects. TLC $=$ total lung capacity. ${ }^{*} P<.05$ comparing EFL and control. $† P<.05$ comparing subjects with EFL and with no EFL. $¥ P<.05$ comparing subjects with no EFL and controls.

that significant tidal F-V enveloping at rest identified a subgroup of COPD subjects who presented with earlier ventilatory constraints and higher dyspnea perception during exercise. This subgroup showed excessive abdominal muscle recruitment that did not decrease the operating lung volumes. The latter finding, therefore, provides indirect evidence supporting the presence of EFL in subjects displaying significant enveloping. Collectively, these data 

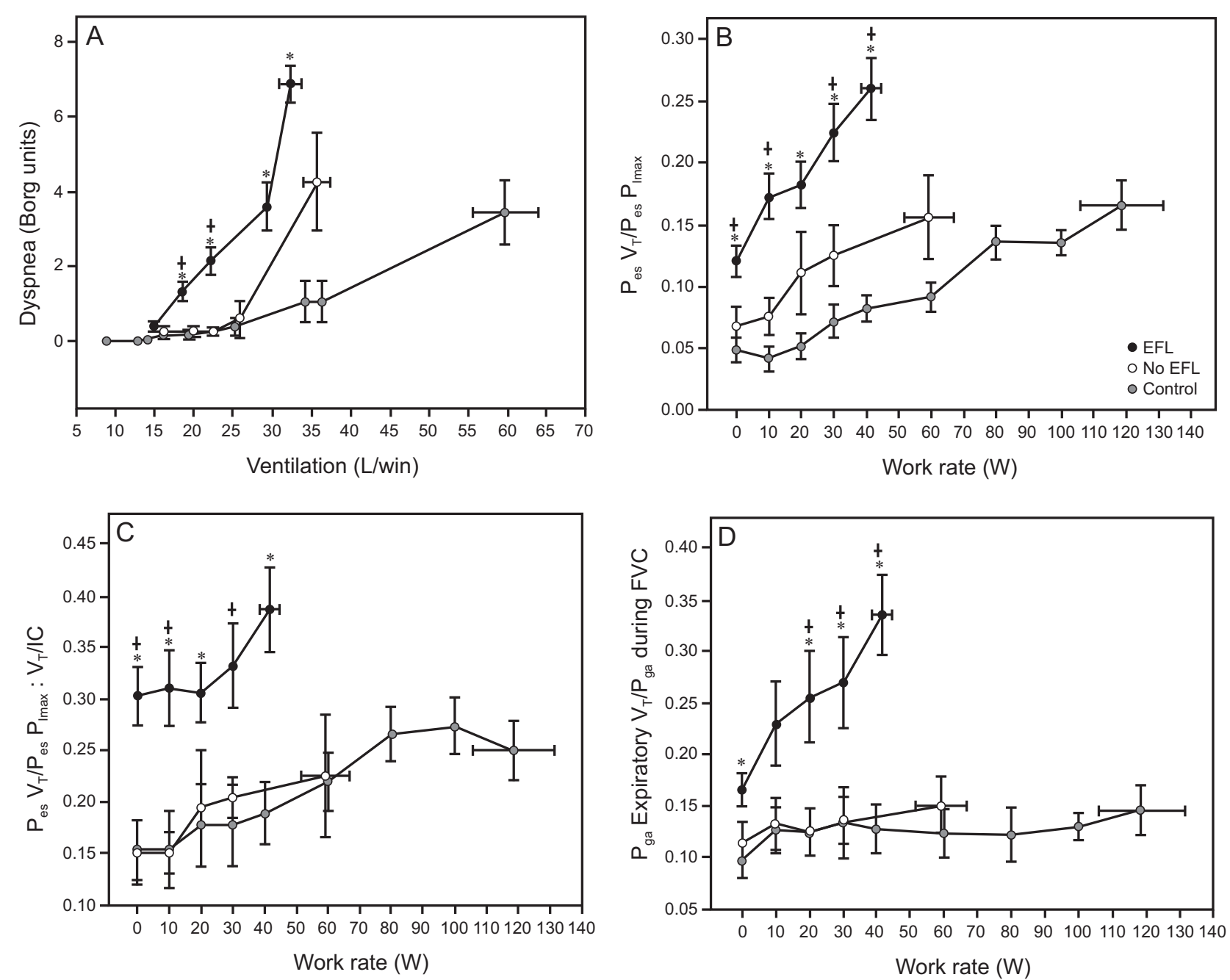

Fig. 4. Dyspnea perception in isoventilation $(A)$ and indexes of tidal respiratory muscle effort (B-D) during exercise in control subjects and subjects with and without tidal expiratory flow limitation (EFL) suggested by significant tidal flow-volume enveloping. $P_{\text {es }} V_{T}=$ esophageal pressure during tidal inspiration; $P_{\text {es }} P_{I m a x}=$ esophageal pressure during baseline maximum inspiratory pressure; $V_{T}=$ tidal volume; $\mathrm{IC}=$ inspiratory capacity; $\mathrm{P}_{\mathrm{ga}}=$ gastric pressure; $\mathrm{FVC}=$ forced vital capacity. ${ }^{*} P<.05$ comparing subjects with $\mathrm{EFL}$ to controls. $\dagger P<.05$ comparing subjects with EFL to those with no EFL.

indicate that, despite its inherent limitations, ${ }^{8-10}$ the assessment of tidal F-V enveloping remains a valid approach, ${ }^{11,13,33}$ which translates into clinically meaningful outcomes in subjects with moderate-to-severe COPD.

In patients with obstructive airway disease, there is well-established evidence that the increase in operational lung volumes, as assessed with serial inspiratory capacity maneuvers, correlates more strongly to exercise endurance and dyspnea than traditional metrics of air-flow limitation such as $\mathrm{FEV}_{1} \cdot{ }^{34}$ The detection of significant EFL at rest with F-V loop analysis has the potential to predict the development of mechanical ventilatory constraints on exercise in patients with COPD. ${ }^{4}$ This is of particular relevance because there is a paucity of pulmonary function parameters to unequivocally predict these critical abnormalities. ${ }^{1}$ In this study, signifi- cant EFL at rest distinguished subjects with COPD who presented with dynamic hyperinflation (Fig. 3B) with earlier mechanical constraints to tidal volume expansion (Fig. 3D). Increased neural drive and inspiratory muscle effort due to increased elastic loading, decreased dynamic compliance, and increased resistive loading of the respiratory muscles ${ }^{4}$ were likely relevant to explain the concomitant increase in dyspnea perception (Fig. 3F). Accordingly, the rise in dyspnea perception was accompanied by physiological evidence of neuromechanical dissociation (Fig. 4C). On the other hand, EFL- subjects presented an intermediate exercise response pattern between healthy controls and EFL + subjects. These findings are in agreement with previous studies correlating the presence of resting EFL with altered exertional respiratory mechanics ${ }^{35-37}$ and worse exercise 
Table 3. Baseline Characteristics Comparing COPD Subjects With Significant Tidal Flow-Volume Loop Enveloping at Rest

\begin{tabular}{|c|c|c|}
\hline \multirow{2}{*}{ Variables } & \multicolumn{2}{|c|}{$\operatorname{COPD}(n=31)$} \\
\hline & Excessive Abdominal Recruitment $(n=16)$ & Nonexcessive Abdominal Recruitment $(n=15)$ \\
\hline Male sex, $n(\%)$ & $8(50)$ & $7(47)$ \\
\hline Age, y & $60.6 \pm 9.1$ & $63.0 \pm 10.8$ \\
\hline Weight, kg & $68.8 \pm 14.5$ & $64.2 \pm 13.8$ \\
\hline Height, cm & $161.5 \pm 8.5$ & $163.3 \pm 7.5$ \\
\hline Body mass index, $\mathrm{kg} / \mathrm{m}^{2}$ & $26.5 \pm 5.6$ & $23.9 \pm 4.3$ \\
\hline \multicolumn{3}{|l|}{ Resting lung function } \\
\hline $\mathrm{FEV}_{1}, \mathrm{~L}$ & $0.95 \pm 0.29 \dagger$ & $1.06 \pm 0.40 \dagger$ \\
\hline $\mathrm{FEV}_{1}, \%$ predicted & $35 \pm 11 \dagger$ & $38 \pm 13 \dagger$ \\
\hline $\mathrm{FEV}_{1}$ post $\mathrm{BD}, \mathrm{L}$ & $1.01 \pm 0.30$ & $1.15 \pm 0.52$ \\
\hline $\mathrm{FEV}_{1}$ post $\mathrm{BD}, \%$ predicted & $37 \pm 11$ & $41 \pm 17$ \\
\hline FVC, L & $1.91 \pm 0.51 \dagger$ & $1.97 \pm 0.59 \dagger$ \\
\hline FVC, $\%$ predicted & $55 \pm 12 \dagger$ & $56 \pm 15 \dagger$ \\
\hline FVC post $\mathrm{BD}, \mathrm{L}$ & $2.04 \pm 0.50$ & $2.21 \pm 0.67$ \\
\hline FVC post $\mathrm{BD}, \%$ predicted & $58 \pm 11$ & $62 \pm 15$ \\
\hline $\mathrm{FEV}_{1} / \mathrm{FVC}, \%$ & $50 \pm 11 \dagger$ & $54 \pm 10 \dagger$ \\
\hline $\mathrm{FEV}_{1} / \mathrm{FVC}$ post $\mathrm{BD}, \%$ & $50 \pm 13$ & $50 \pm 11$ \\
\hline TLC, L & $7.29 \pm 1.81 \dagger$ & $7.20 \pm 1.16 \dagger$ \\
\hline TLC, $\%$ predicted & $138 \pm 23 \dagger$ & $135 \pm 17 \dagger$ \\
\hline Residual volume, $\mathrm{L}$ & $5.28 \pm 1.50 \dagger$ & $4.95 \pm 1.15 \dagger$ \\
\hline Residual volume, $\%$ predicted & $304 \pm 80 \dagger$ & $281 \pm 77 \dagger$ \\
\hline $\mathrm{FRC}, \mathrm{L}$ & $5.57 \pm 1.80 \dagger$ & $5.74 \pm 1.28 \dagger$ \\
\hline FRC, \% predicted & $180 \pm 53 \dagger$ & $183 \pm 41 \dagger$ \\
\hline $\mathrm{D}_{\mathrm{LCO}} \mathrm{SB}, \%$ predicted & $21 \pm 4 \dagger$ & $13 \pm 6 \dagger$ \\
\hline VA SB, L & $3.59 \pm 0.86 \dagger$ & $3.92 \pm 1.21 \dagger$ \\
\hline VA, $\%$ predicted & $66 \pm 9 \dagger$ & $72 \pm 19 \dagger$ \\
\hline $\mathrm{P}_{\text {Imax }}, \mathrm{cm} \mathrm{H}_{2} \mathrm{O}$ & $-70.4 \pm 14.7 \dagger$ & $-72.5 \pm 22.6 \dagger$ \\
\hline $\mathrm{P}_{\text {Imax }}, \%$ predicted & $65 \pm 13 \dagger$ & $73 \pm 23 \dagger$ \\
\hline $\mathrm{P}_{\text {Emax }}, \mathrm{cm} \mathrm{H}_{2} \mathrm{O}$ & $89.4 \pm 12.3$ & $102.7 \pm 38.9$ \\
\hline $\mathrm{P}_{\text {Emax }}, \%$ predicted & $77 \pm 13 \dagger$ & $91 \pm 36$ \\
\hline \multicolumn{3}{|c|}{ 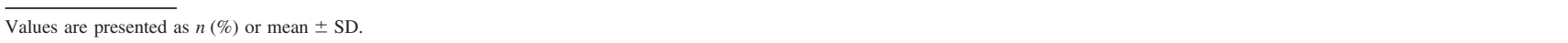 } \\
\hline \multirow{2}{*}{\multicolumn{3}{|c|}{$\begin{array}{l}\dagger P<.05 \text { compared to the control group (data in Table } 1 \text { ). } \\
\ddagger P<.05 \text { between COPD groups. }\end{array}$}} \\
\hline & & \\
\hline \multicolumn{3}{|c|}{$\mathrm{BD}=$ bronchodilator } \\
\hline \multicolumn{3}{|l|}{$\mathrm{TLC}=$ total lung capacity } \\
\hline \multicolumn{3}{|c|}{$\mathrm{FRC}=$ functional residual capacity } \\
\hline \multicolumn{3}{|c|}{$\begin{array}{l}\mathrm{D}_{\mathrm{LCO}}=\text { diffusing capacity of the lung for carbon monoxide } \\
\mathrm{VA}=\text { alveolar volume }\end{array}$} \\
\hline \multirow{2}{*}{\multicolumn{3}{|c|}{$\begin{array}{l}\mathrm{VA}=\text { alveolar volume } \\
\mathrm{SB}=\text { single breath }\end{array}$}} \\
\hline & $\mathrm{SB}=$ single breath & \\
\hline $\mathrm{P}_{\mathrm{Imax}}=$ maximum inspiratory pressure & & \\
\hline $\mathrm{P}_{\mathrm{Emax}}=$ maximum expiratory pressure & & \\
\hline
\end{tabular}

capacity $^{35,37}$ and dyspnea ${ }^{37}$ using several different techniques (eg, negative expiratory pressure, ${ }^{35}$ manual compression of the abdominal wall, ${ }^{36}$ and analysis of the extension of the expiratory F-V loop concavity $\left.{ }^{37}\right)$. In fact, interventions known to be effective in improving dyspnea and exercise tolerance in patients with COPD (eg, bronchodilators, ${ }^{38}$ double lung transplantation ${ }^{39}$ ) successfully attenuated the resting encroachment of the expiratory limb of the tidal F-V into the maximum F-V loop.

Plotting the tidal F-V loops within the maximum envelope is the only method currently integrated into most of the commercially available, computerized CPET systems. ${ }^{40}$ This method also has the clinical advantage of simplicity, although new advances, such as the breath-by-breath quantification of progressive air-flow limitation by spontaneous expiratory F-V curve configuration analysis, might further improve accuracy and reproducibility. ${ }^{37,41}$ It is also noteworthy that modern technology allows the correct placement of the tidal F-V loops within the theoretical maximum envelope when an inspiratory capacity maneuver is performed together with the tidal loops. ${ }^{4}$ In fact, this is a key feature to allow a valid comparison between tidal and maximum F-V loops. It is therefore mandatory that a 

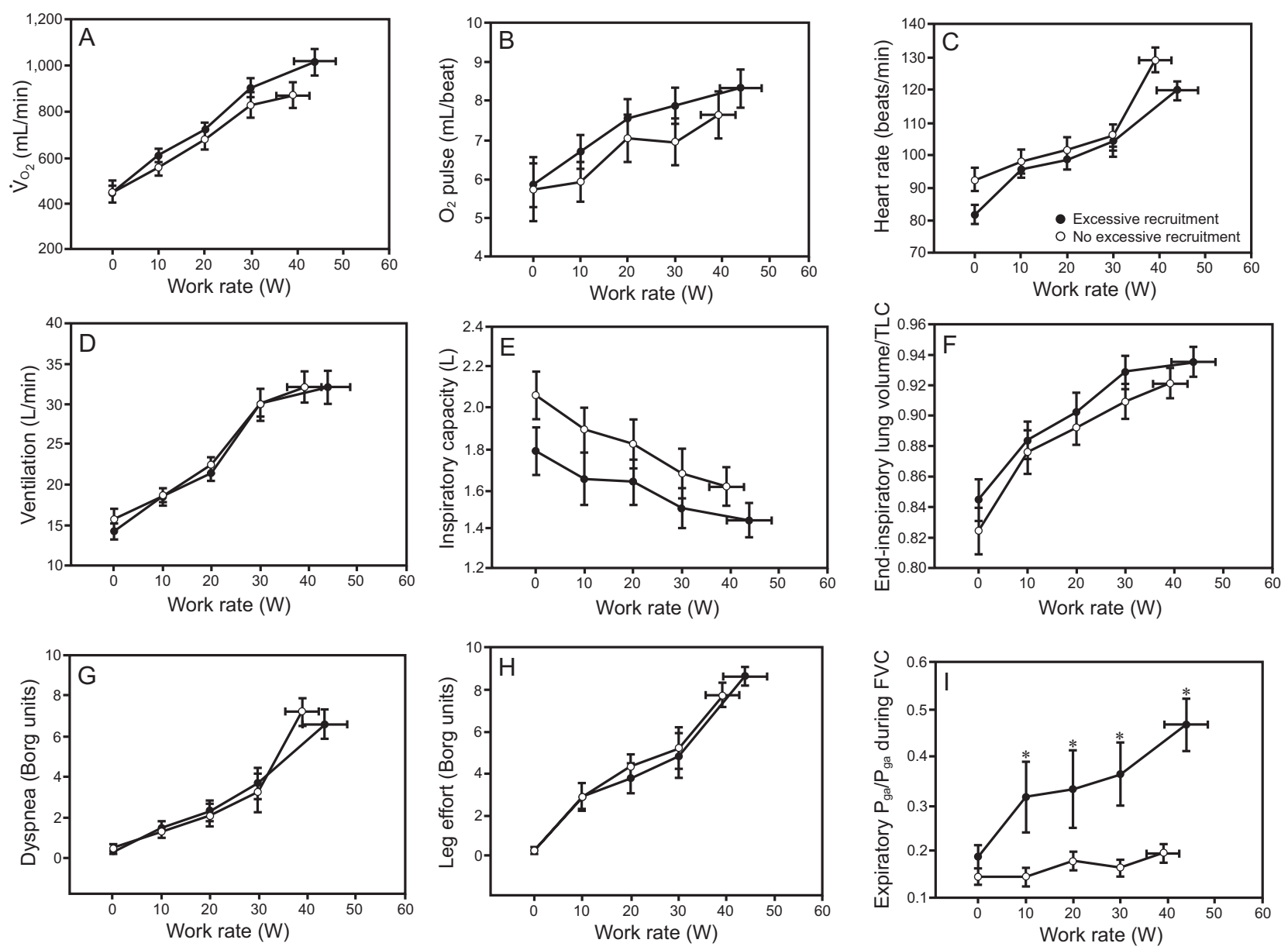

Fig. 5. Exercise responses in subjects with COPD presenting with significant tidal flow-volume enveloping with and without excessive exercise expiratory muscle recruitment (ie, an increase in gastric pressure $\geq 15 \%$ during tidal expiration). $\dot{\mathrm{V}}_{\mathrm{O}_{2}}=$ oxygen consumption; TLC = total lung capacity; $\mathrm{P}_{\text {ga }}=$ gastric pressure; $\mathrm{FVC}=$ forced vital capacity. ${ }^{*} P<.05$ between groups.

patient performs an inspiratory capacity maneuver during the assessment of any enveloping. ${ }^{11}$

Given the vast heterogeneity of COPD, it is not surprising that the effect of a given therapy on dyspnea and exercise intolerance varies among patients. ${ }^{42,43}$ As previously mentioned, the detection of significant EFL at rest provides valuable noninvasive anticipation of worse dynamic respiratory mechanics during exercise. From a practical perspective, this can be used as an indication that the mechanical ventilatory constraints may be relevant to breathlessness and exercise intolerance in individual subjects. ${ }^{44}$ This might have a relevant impact on clinical decision-making concerning optimization or stepping-up therapy for patients with COPD. For instance, if significant ventilatory limitation to exercise is anticipated, attempts to improve dyspnea should focus mainly on interventions to improve mechanical ventilatory constraints (ie, decreasing lung hyperinflation). Rehabilitation strategies to improve peripheral muscle capillarization and bioenergetics (ie, exercise training), ${ }^{45}$ on the other hand, may be less effective in this scenario. The validity of this line of reasoning remains to be determined.

Excessive expiratory muscle effort during exercise was observed exclusively in the EFL + subjects, and it did not mitigate progressive dynamic hyperinflation (Fig. 5E, 5F). This behavior did not negatively affect cardiovascular and exercise performance. For instance, key parameters intrinsically linked to cardiovascular performance (eg, exercise tolerance, $\mathrm{O}_{2}$ uptake, $\mathrm{O}_{2}$ pulse, and heart rate) were unaltered by this ventilatory strategy (Fig. 5). Although this was not a priori hypothesis of our study, we did not detect a signal linking excessive positive expiratory pressure during exercise with negative hemodynamic effects. ${ }^{1,46}$

This study has some limitations. Thoracic gas compression due to maximum expiratory effort can underestimate the true maximum expiratory envelope obtained with an FVC maneuver. ${ }^{8-10}$ Moreover, the size of this convenience sample may have precluded the detection of some subtle differences between COPD subgroups. Nevertheless, F-V 


\section{Tidal Flow-Volume Loop Enveloping in Advanced COPD}

loop enveloping identified subjects with COPD with worse exercise performance and dyspnea. Due to technical limitations, we were unable to obtain pressure-volume (or flow) curves to correlate with the F-V traces.

\section{Conclusion}

The presence of significant resting tidal F-V enveloping (ie, $>50 \%$ of tidal volume) successfully identified a subgroup of subjects with COPD who developed earlier inspiratory constraints on exertion, thus leading to a higher burden of dyspnea and poor tolerance of physical effort. Despite its inherent limitations, ${ }^{8-10}$ this longstanding method $^{33}$ is clinically valuable because it provides relevant information for the functional assessment of subjects with COPD.

\section{REFERENCES}

1. O'Donnell DE, Laveneziana P, Webb K, Neder JA. Chronic obstructive pulmonary disease: clinical integrative physiology. Clin Chest Med 2014;35(1):51-69.

2. Langer D, Ciavaglia CE, Neder JA, Webb KA, O'Donnell DE. Lung hyperinflation in chronic obstructive pulmonary disease: mechanisms, clinical implications and treatment. Expert Rev Respir Med 2014; 8(6):731-749.

3. Laveneziana P, Webb KA, Wadell K, Neder JA, O'Donnell DE. Does expiratory muscle activity influence dynamic hyperinflation and exertional dyspnea in COPD? Respir Physiol Neurobiol 2014; 199:24-33.

4. O'Donnell DE, Elbehairy AF, Berton DC, Domnik NJ, Neder JA. Advances in the Evaluation of Respiratory Pathophysiology during Exercise in Chronic Lung Diseases. Front Physiol 2017;8:82.

5. Takara LS, Cunha TM, Barbosa P, Rodrigues MK, Oliveira MF, Nery LE, et al. Dynamics of chest wall volume regulation during constant work rate exercise in patients with chronic obstructive pulmonary disease. Braz J Med Biol Res 2012;45(12):1276-1283.

6. Gruenberger JB, Vietri J, Keininger DL, Mahler DA. Greater dyspnea is associated with lower health-related quality of life among European patients with COPD. Int J Chron Obstruct Pulmon Dis 2017;12:937-944.

7. O'Donnell DE, Elbehairy AF,Domnik NJ, Vincent S, Guenette J, Webb K, Neder KA. Patterns of cardiopulmonary response to exercise in COPD. In: Palange P, Laveneziana P, NederJA, Ward SA. Clinical Exercise Testing (ERS Monograph). Sheffield, European Respiratory Society;2018:107-127.

8. Calverley PM, Koulouris NG. Flow limitation and dynamic hyperinflation: key concepts in modern respiratory physiology. Eur Respir J 2005;25(1):186-199.

9. Tantucci C. Expiratory flow limitation definition, mechanisms, methods, and significance. Pulm Med 2013;2013;749860.

10. Dominelli PB, Sheel AW. Experimental approaches to the study of the mechanics of breathing during exercise. Respir Physiol Neurobiol 2012;180(2-3):147-161.

11. Johnson BD, Weisman IM, Zeballos RJ, Beck KC. Emerging concepts in the evaluation of ventilatory limitation during exercise: the exercise tidal flow-volume loop. Chest 1999;116(2):488-503.

12. Koulouris NG, Valta P, Lavoie A, Corbeil C, Chassé M, Braidy J, et al. A simple method to detect expiratory flow limitation during spontaneous breathing. Eur Respir J 1995;8(2):306-313.
13. Babb TG. Mechanical ventilatory constraints in aging, lung disease, and obesity: perspectives and brief review. Med Sci Sports Exerc 1999;31(1 Suppl):S12-S22.

14. Ingram RH, Schilder DP. Effect of thoracic gas compression on the flow-volume curve of the forced vital capacity. Am Rev Respir Dis 1966;94(1):56-63.

15. Piirilä PL, Hodgson U, Wuorimaa T, Smith HJ, Sovijärvi AR. Thoracic gas compression during forced expiration in patients with emphysema, interstitial lung disease and obesity. BMC Pulm Med 2014; 14:34.

16. Vogelmeier CF, Criner GJ, Martinez FJ, Anzueto A, Barnes PJ, Bourbeau J, et al. Global Strategy for the Diagnosis, Management and Prevention of Chronic Obstructive Lung Disease 2017 Report: GOLD Executive Summary Respirology 2017;22(3):575-601.

17. Miller MR, Hankinson J, Brusasco V, Burgos F, Casaburi R, Coates A, et al. Standardisation of spirometry. Eur Respir J 2005;26(2): 319-338.

18. Macintyre N, Crapo RO, Viegi G, Johnson DC, van der Grinten CP, Brusasco V, et al. Standardisation of the single-breath determination of carbon monoxide uptake in the lung. Eur Respir J 2005;26(4): 720-735.

19. Wanger J, Clausen JL, Coates A, Pedersen OF, Brusasco V, Burgos F, et al. Standardisation of the measurement of lung volumes. Eur Respir J 2005;26(3):511-522.

20. Society ATSER. ATS/ERS Statement on respiratory muscle testing. Am J Respir Crit Care Med 2002;166(4):518-624.

21. Pereira CA, Sato T, Rodrigues SC. New reference values for forced spirometry in white adults in Brazil. J Bras Pneumol 2007;33(4): 397-406.

22. Neder JA, Andreoni S, Castelo-Filho A, Nery LE. Reference values for lung function tests. I. Static volumes. Braz J Med Biol Res 1999;32(6):703-717.

23. Neder JA, Andreoni S, Peres C, Nery LE. Reference values for lung function tests. III. Carbon monoxide diffusing capacity (transfer factor). Braz J Med Biol Res 1999;32(6):729-737.

24. Society AT, Physicians ACoC. ATS/ACCP Statement on cardiopulmonary exercise testing. Am J Respir Crit Care Med 2003;167(2): 211-277.

25. Palange P, Ward SA, Carlsen KH, Casaburi R, Gallagher CG, Gosselink R, et al. Recommendations on the use of exercise testing in clinical practice. Eur Respir J 2007;29(1):185-209.

26. Borg GA. Psychophysical bases of perceived exertion. Med Sci Sports Exerc 1982;14(5):377-381.

27. Guenette JA, Chin RC, Cory JM, Webb KA, O'Donnell DE. Inspiratory Capacity during Exercise: Measurement, Analysis, and Interpretation Pulm Med 2013;2013;956081.

28. Plachi F, Balzan FM, Gass R, Dorneles RG, Zambiazi R, da Silva $\mathrm{DP}$, et al. Low exertional inspiratory capacity is not related to dynamic inspiratory muscle weakness in heart failure. Respir Physiol Neurobiol 2018;254:32-35.

29. Balzan FM, da Silva RC, da Silva DP, Sanches PR, Tavares AM, Ribeiro JP, et al. Effects of diaphragmatic contraction on lower limb venous return and central hemodynamic parameters contrasting healthy subjects versus heart failure patients at rest and during exercise. Physiol Rep 2014;2(12).

30. Diaz O, Villafranca C, Ghezzo H, Borzone G, Leiva A, Milic-Emil $\mathrm{J}$, et al. Role of inspiratory capacity on exercise tolerance in COPD patients with and without tidal expiratory flow limitation at rest. Eur Respir J 2000;16(2):269-275.

31. Díaz O, Villafranca C, Ghezzo H, Borzone G, Leiva A, Milic-Emili $\mathrm{J}$, et al. Breathing pattern and gas exchange at peak exercise in COPD patients with and without tidal flow limitation at rest. Eur Respir J 2001;17(6):1120-1127. 


\section{Tidal Flow-Volume Loop Enveloping in Advanced COPD}

32. Elbehairy AF, Ciavaglia CE, Webb KA, Guenette JA, Jensen D, Mourad SM, et al. Pulmonary Gas Exchange Abnormalities in Mild Chronic Obstructive Pulmonary Disease. Implications for Dyspnea and Exercise Intolerance. Am J Respir Crit Care Med 2015;191(12): 1384-1394.

33. Hyatt RE. The interrelationships of pressure, flow, and volume during various respiratory maneuvers in normal and emphysematous subjects. Am Rev Respir Dis 1961;83:676-683.

34. Lange P, Halpin DM, O'Donnell DE, MacNee W. Diagnosis, assessment, and phenotyping of COPD: beyond $\mathrm{FEV}^{1}$. Int J Chron Obstruct Pulmon Dis 2016;11 Spec Iss:3-12.

35. Koulouris NG, Dimopoulou I, Valta P, Finkelstein R, Cosio MG, Milic-Emili J. Detection of expiratory flow limitation during exercise in COPD patients. J Appl Physiol (1985) 1997;82(3):723731.

36. Abdel Kafi S, Sersté T, Leduc D, Sergysels R, Ninane V. Expiratory flow limitation during exercise in COPD: detection by manual compression of the abdominal wall. Eur Respir J 2002;19(5):919-927.

37. Varga J, Casaburi R, Ma S, Hecht A, Hsia D, Somfay A, et al. Relation of concavity in the expiratory flow-volume loop to dynamic hyperinflation during exercise in COPD. Respir Physiol Neurobiol 2016;234:79-84.

38. Belman MJ, Botnick WC, Shin JW. Inhaled bronchodilators reduce dynamic hyperinflation during exercise in patients with chronic obstructive pulmonary disease. Am J Respir Crit Care Med 1996;153(3): 967-975.

39. Martinez FJ, Orens JB, Whyte RI, Graf L, Becker FS, Lynch JP. Lung mechanics and dyspnea after lung transplantation for chronic airflow obstruction. Am J Respir Crit Care Med 1996; 153(5):1536-1543

40. Stickland MK, Butcher SJ, Marciniuk DD, Bhutani M. Assessing exercise limitation using cardiopulmonary exercise testing. Pulm Med 2012;824091, 2012.

41. Ma S, Hecht A, Varga J, Rambod M, Morford S, Goto S, et al. Breath-by-breath quantification of progressive airflow limitation during exercise in COPD: a new method. Respir Med 2010;104(3):389396

42. Han MK, Agusti A, Calverley PM, Celli BR, Criner G, Curtis JL, et al. Chronic obstructive pulmonary disease phenotypes: the future of COPD. Am J Respir Crit Care Med 2010;182(5):598-604.

43. Singh D, Roche N, Halpin D, Agusti A, Wedzicha JA, Martinez FJ. Current Controversies in the Pharmacological Treatment of Chronic Obstructive Pulmonary Disease. Am J Respir Crit Care Med 2016; 194(5):541-549.

44. Neder JA, Berton DC, Rocha A, Arbex FF, Alencar MC, DeganiCosta LH, et al. Abnormal patterns of response to incremental CPET. In: Palange P, Laveneziana P, Neder JA, Ward SA, editors. Clinical Exercise Testing (ERS Monograph): European Respiratory Society; 2018:34-58.

45. Spruit MA, Singh SJ, Garvey C, ZuWallack R, Nici L, Rochester C, et al. An official American Thoracic Society/European Respiratory Society statement: key concepts and advances in pulmonary rehabilitation. Am J Respir Crit Care Med 2013;188(8):e13-e64.

46. Stark-Leyva KN, Beck KC, Johnson BD. Influence of expiratory loading and hyperinflation on cardiac output during exercise. J Appl Physiol (1985) 2004;96(5):1920-1927.

This article is approved for Continuing Respiratory Care Education credit. For information and to obtain your CRCE

(free to AARC members) visit

www.rcjournal.com

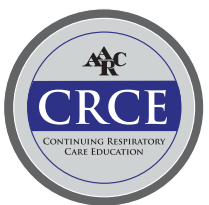

